\title{
Azeotropic points with relative volatility-prediction and calculation
}

\author{
Saida Fedali*, Hakim Madani \\ Department of Mechanics, Faculty of Technology, Laboratory of Studies of the Industrial Energy \\ Systems (LESEI), University of Batna, Algeria \\ Email: saida_fedali@yahoo.fr
}

\begin{abstract}
In this study, we predict the locus of azeotropes for binary mixtures by using the relative volatility is presented. A simple method is used in binary mixtures: At first we applied the method which is based on experimental data and then we evaluated by thermodynamic model. The model composed:

- $\quad$ Peng-Robinson equation of state

- Mathias-Copeman alpha function

- Wong-Sandler mixing rules

- $\quad$ NRTL model

1,1-difluoroethane (R152a) + n-butane (R600), carbon dioxide (R744) + 1,1-difluoroethane (R152a) and 1,1,1,2-Tétrafluoroéthane (R134a) + 1,1-difluoroethane (R152a) are the binary mixtures used in this work. The results confirm that there is a good agreement between the predicted values and the experimental data and the relative error does not exceed $1 \%$ for the molar fraction and $0.5 \%$ for the pressure. In conclusion, this method is considered able to predict the azeotropic location.
\end{abstract}

Keywords: Equation of State, Mixing Rules, Excess Free Energy, Azeotrope, Relative Volatility.

\section{INTRODUCTION}

In order to overcome the problem of locating azeotropic point that arises in the field of refrigeration and distillation. Diverse methods are used: experimental and thermodynamic model (Peng-Robinson equation of state; Mathias-Copeman alpha function; Wong-Sandler mixing rules; NRTL model, etc.).

The repeated condensation and evaporation processes in refrigeration process modify the composition of the azeotropic mixtures and their thermodynamic properties. So, this causes a lag in the boiling and condensation temperature at constant pressure. The heat capacity and heat of vaporization change, this leads to changing the refrigeration process performances.

Our interest is to correctly predict the azeotropic property of binary mixtures. As an illustration of this idea, we presented simple model for predicting the azeotropic behavior in refrigeration binary mixtures and for establish the best composition for the best performance. Besides, we try to find refrigerant blends compatible with existing refrigerating machines and having similar characteristics similar characteristics to the use CFCs. This method based on experimental data and thermodynamic model. We have applied them to binary mixtures R152a + R600 [2], R744 + R152a [1] and R134a + R152a [3].

\section{METHODS}

Here, we predict the azeotropic location for refrigerant binary mixtures by the combination of approach which is based on experimental data and an accurate thermodynamic model is necessary, to validate the obtained results. This model focuses on two approaches. A schematic diagram of our model is presented in Figure 1.

In the first approach, we use the experimental data of binary mixtures, with calculated volatility $\left(\alpha_{12}\right)$ to find the most volatile component. Afterwards, we utilize Microsoft Excel as a powerful tool to meet the major needs of data analysis and modeling.

In the second approach, in order to estimate and describe the behavior of both azeotropic and critical point, it is important to carefully consider the choice of equations namely, the Peng-Robinson [4], with Mathias-Copeman alpha function [5]. For excellent representation of vaporliquid equilibrium, we used Wong-Sandler [6] mixing rules with NRTL [7] excess free energy $\left(\mathrm{G}^{\mathrm{E}}\right)$ model.

The aim is to develop reliable prediction methods, which can predict the azeotropic point and determine the critical point. Because, it is rare to find experimental data covering a wide range of operating conditions for refrigerants used in industrial refrigeration with air conditioning and which can be measured. 


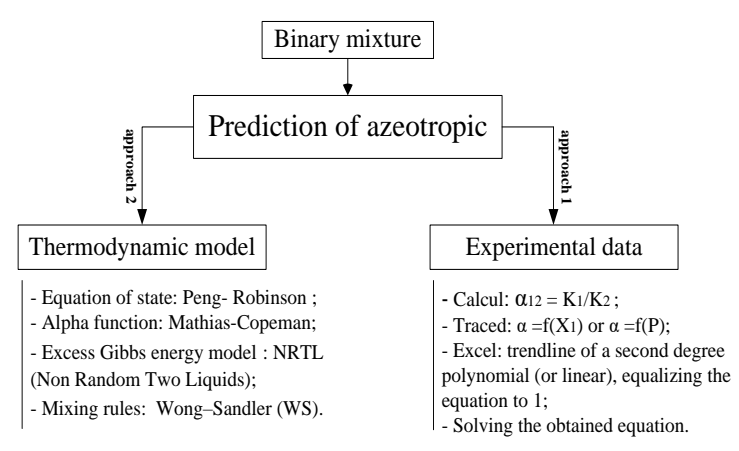

Figure 1. Diagram of the prediction model

\subsection{Approach 1 (Experimental data)}

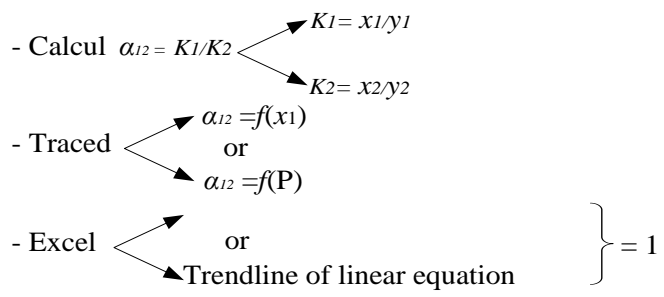

- Solving the equation

We applied the method which is based on experimental data for calculation and prediction of azeotropes, and then the developed method is validated using a thermodynamic model.

\subsection{Approach 2 (Thermodynamic model)}

The developed model is based on a simple correlation schema. Such model allows knowing if an azeotrope may be obtained or not in binary refrigerant mixtures.

The Peng-Robinson EoS [4] :

$P=\frac{R T}{v-b}-\frac{a(T)}{\left(v^{2}+2 v b-v^{2}\right)}$

with :

$a=0,457240 \frac{R^{2} T_{C}^{2}}{P_{C}}$

$b=0,07780 \frac{R T_{c}}{P_{c}}$

Mathias-Copeman alpha function, [5] :

$\alpha(T)=\left[1+c_{1}\left(1-T_{r}^{0,5}\right)+c_{2}\left(1-T_{r}^{0,5}\right)^{2}+c_{3}(1-\right.$

$\left.\left.T_{r}^{0,5}\right)^{3}\right]^{2}$

if $\mathrm{T}>\mathrm{T}_{\mathrm{C}}$

$\alpha(T)=\left[1+c_{1}\left(1-T_{r}^{0,5}\right)\right]^{2}$

where $c_{1}, c_{2}$ and $c_{3}$ are adjustable parameters.

The Wong-Sandler [6] mixing rules are chosen from the good representation of the vapor-liquid equilibrium, for EoS Peng-Robinson which are given by:

$$
\begin{gathered}
b=\frac{\sum_{i} \sum_{j} x_{i} x_{j}\left(b-\frac{a}{R T}\right)}{1-\left(\frac{\sum_{i} x_{i} \frac{a_{i}}{b_{i}}}{R T}+\frac{g_{\gamma}^{E}(T, P, x)}{C R T}\right)} \\
b-\frac{a}{R T}=\sum_{i} \sum_{j} x_{i} x_{j}\left(b-\frac{a}{R T}\right)_{i j}
\end{gathered}
$$

$\left(b-\frac{a}{R T}\right)_{i j}=\frac{1}{2}\left[\left(b-\frac{a}{R T}\right)_{i}+\left(b-\frac{a}{R T}\right)_{j}\right]\left(1-k_{i j}\right)$

$\mathrm{K}_{\mathrm{ij}}$ is an adjustable binary interaction parameter and $C$ is a numerical constant which depends on the EoS.

The component activity parameters of binary mixture systems are calculated with the NRTL (Non Random Two Liquids) model [7]:

$$
\operatorname{Ln} \gamma_{i}=\frac{\sum_{j=1}^{n} \tau_{j i} G_{j i} x_{j}}{\sum_{k=1}^{n} G_{k i} x_{k}}+\sum_{j=1}^{n} \frac{x_{j} G_{i j}}{\sum_{k=1}^{n} G_{k i} x_{k}}\left(\tau_{i j}-\frac{\sum_{k=1}^{n} x_{k} \tau_{k j} G_{k j}}{\sum_{k=1}^{n} G_{k i} x_{k}}\right)
$$

where the model parameters $\mathrm{C}_{\mathrm{ij}}$ and $\mathrm{G}_{\mathrm{ij}}$ are defined as follows:

$$
\begin{aligned}
& C_{j i}=\frac{\tau_{i j}}{R T} \\
& G_{i j}=\exp \left(-\alpha_{j i} \frac{\tau_{j i}}{R T}\right) \\
& \tau_{i i}=\tau_{j j}=0
\end{aligned}
$$

\section{RESULTS}

Our objective is to applied this method for judged if can be obtained or not an azeotropic point in binary refrigerant mixtures (in order to generalize this method for all binary mixtures). The binary components data from experiment and calculation are all listed in Table 1 and 2. Summary of the $x_{a z}$ (mole fraction) and $P_{a z}$ (pressure) in Table 3. For each isotherm was calculated the value of the partition coefficient $K_{l}$.

For each isotherm was calculated the value of the partition coefficient $K_{1}$ and $K_{2}$. Afterwards, we calculate the value of relative volatility $\left(\alpha_{12}=K_{1} / K_{2}\right)$. To determine the position of azeotropic point, we scheme $\alpha_{12}$ according to the mole fraction $x_{I}$ (1: For the most volatile pure substance). In addition, we applied the similar steps for pressure ( $\alpha$ according to the pressure). The relative deviations are plotted in Figure 2 and Figure 3. 
Table 1. Temperatures, molar fractions and $K_{l}$ partition coefficient of the most volatile pure component in the $\mathrm{R} 152 \mathrm{a}+\mathrm{R} 600$ system

\begin{tabular}{llllll}
\hline $\mathrm{T} / \mathrm{K}$ & $x_{0}$ & $\mathrm{~K}_{1}$ & $x_{\mathrm{f}}$ & $\mathrm{K}_{1}$ & \\
\hline 278.15 & 0.0680 & 4.8529 & 0.9410 & 0.9809 & yes \\
\hline 283.15 & 0.0600 & 4.9000 & 0.9530 & 0.9832 & yes \\
\hline 293.15 & 0.0900 & 3.9444 & 0.9510 & 0.9842 & yes \\
\hline 303.15 & 0.0650 & 4.4000 & 0.9560 & 0.9937 & yes \\
\hline 313.15 & 0.0950 & 3.5895 & 0.9380 & 0.9883 & yes \\
\hline 323.15 & 0.1070 & 3.1963 & 0.9530 & 0.9906 & yes \\
\hline
\end{tabular}

Table 2. Temperatures, mole fractions and $K_{l}$ partition coefficient of the most volatile pure component in the R744 + R152a system

\begin{tabular}{llllll}
\hline $\mathrm{T} / \mathrm{K}$ & $x_{0}$ & $\mathrm{~K}_{1}$ & $x_{\mathrm{f}}$ & $\mathrm{K}_{1}$ & \\
\cline { 1 - 5 } 258.44 & 0.1241 & 5.0475 & 0.8586 & 1.1414 & no \\
\hline 278.25 & 0.1424 & 4.2282 & 0.8516 & 1.1369 & no \\
\hline 298.84 & 0.0539 & 5.2152 & 0.9354 & 1.0414 & no \\
\hline 308.37 & 0.0722 & 4.3726 & 0.9152 & 1.0388 & no \\
\hline 323.30 & 0.0743 & 3.7524 & 0.8088 & 1.0537 & no \\
\hline 343.20 & 0.0826 & 2.9056 & 0.5941 & 1.1294 & no \\
\hline
\end{tabular}

Table 3 .Mole fractions and vapour pressures of the azeotropic mixture (R152a + R600)

\begin{tabular}{lllll}
\hline $\mathrm{T} / \mathrm{K}$ & $x_{\mathrm{az}(\operatorname{Exp})}$ & $x_{\mathrm{az}(\mathrm{Cal})}$ & $\mathrm{P}_{\mathrm{az}(\mathrm{Exp})}$ & $\mathrm{P}_{\mathrm{az}(\mathrm{Cal})}$ \\
\hline 273.15 & 0.8380 & 0.8459 & 0.2810 & 0.2824 \\
283.15 & 0.8400 & 0.8448 & 0.3950 & 0.3939 \\
293.15 & 0.8410 & 0.8466 & 0.5360 & 0.5382 \\
303.15 & 0.8470 & 0.8471 & 0.7140 & 0.7138 \\
313.15 & 0.8510 & 0.8495 & 0.9330 & 0.9367 \\
323.15 & 0.8530 & 0.8515 & 1.2020 & 1.2017 \\
\hline
\end{tabular}

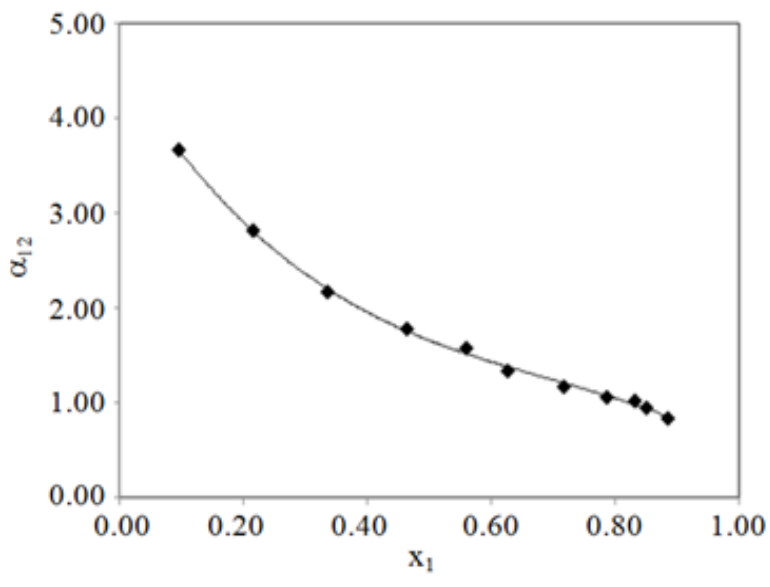

$-a-$

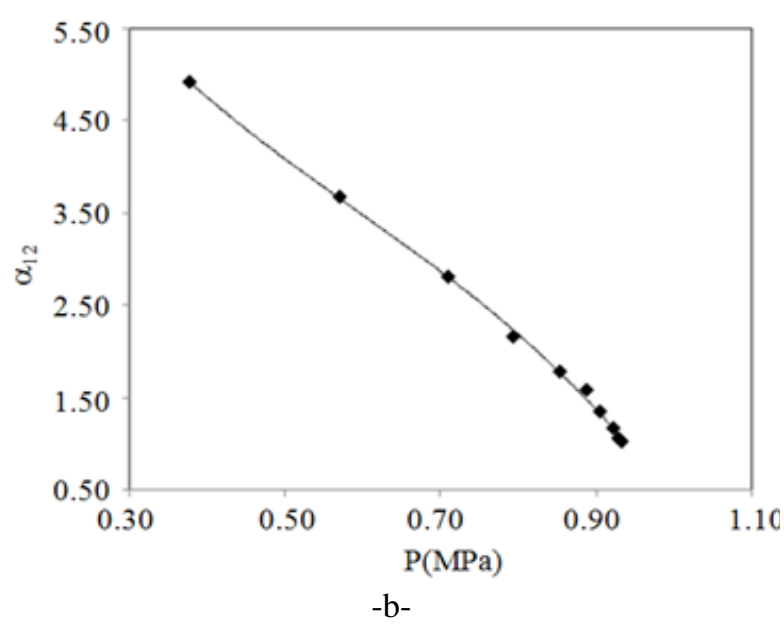

Figure 2. Relative volatility according to molar fraction (a) and pressure (b) for R152a + R600 system
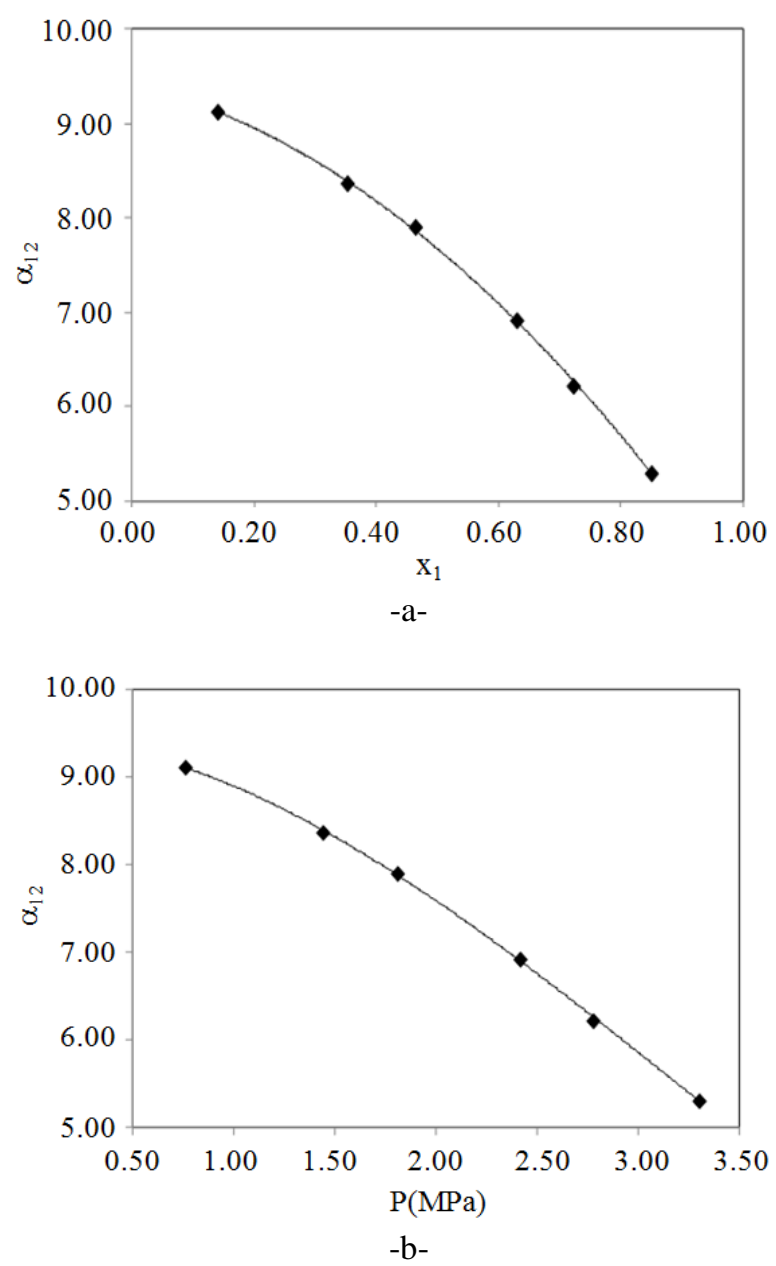

Figure 3. Relative volatility according to molar fraction (a) and pressure (b) for R744 + R152a system

Additionally, average deviation values of mole fraction and pressure are given in Figure 4. 

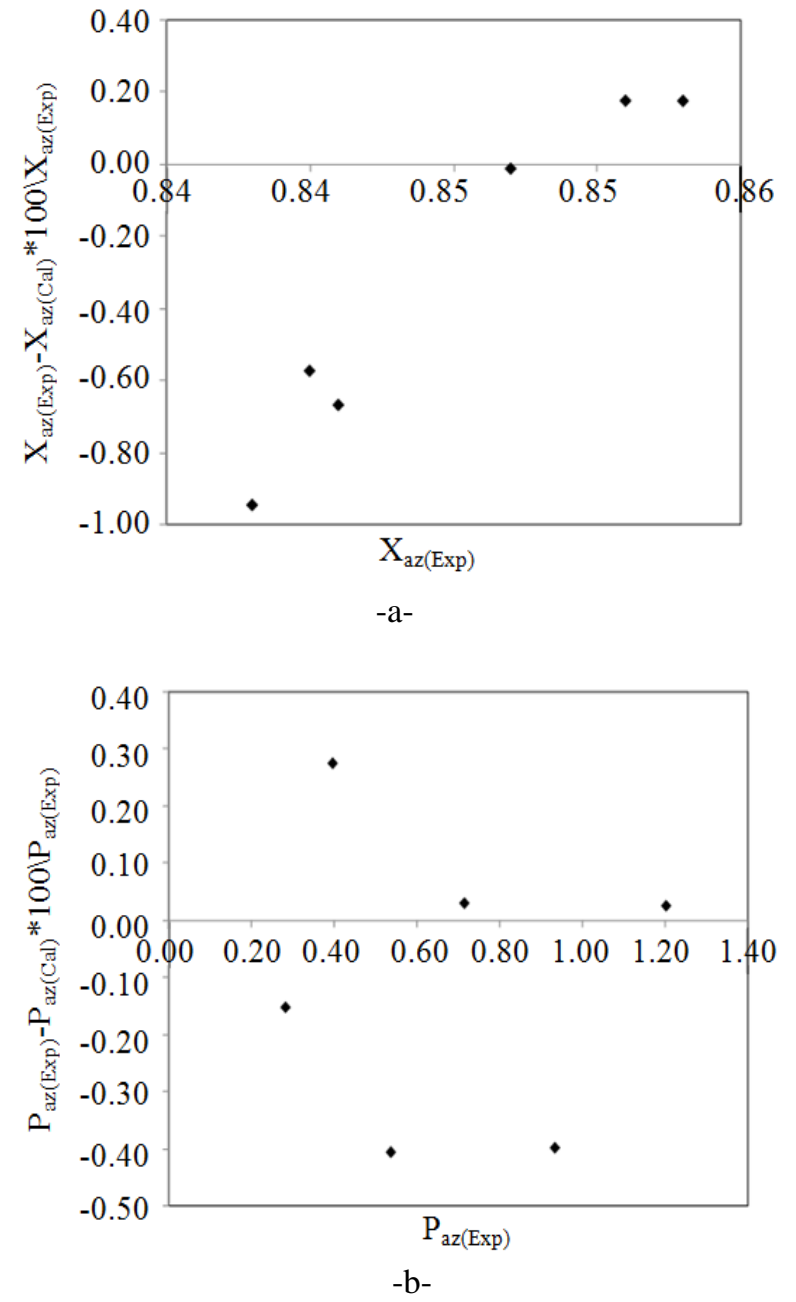

Figure 4. Relative deviations of mole fractions (a) and vapour pressures (b) of the azeotropic mixture

$$
\mathrm{R} 152 \mathrm{a}+\mathrm{R} 600
$$

In addition, it is necessary to confirm these results by using thermodynamic model, which is presented in Figures 5, 6 and 7. This method is able to predict of binary azeotrope position in a wide variety of mixtures.

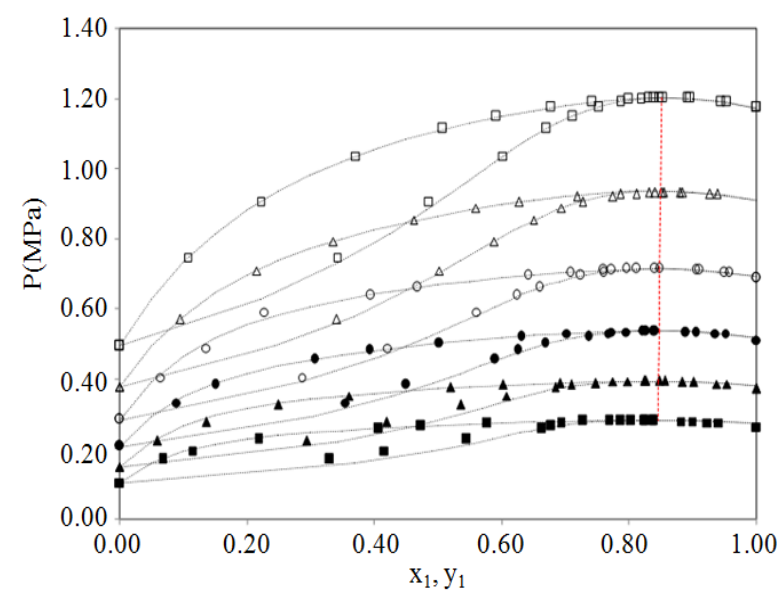

Figure 5. Compare the results of our work with experimental data [2] for R152a + R600 system, ( $\mathbf{\square}) 273.15 \mathrm{~K}$, ( $\mathbf{\Delta}) 283.15$, (•) $293.15 \mathrm{~K},(\bigcirc) 303.15 \mathrm{~K},(\Delta) 313.15 \mathrm{~K}$, () $323.15 \mathrm{~K}$; ---- azeotrope line, dotted line, calculated from PR-MC-WSNRTL model

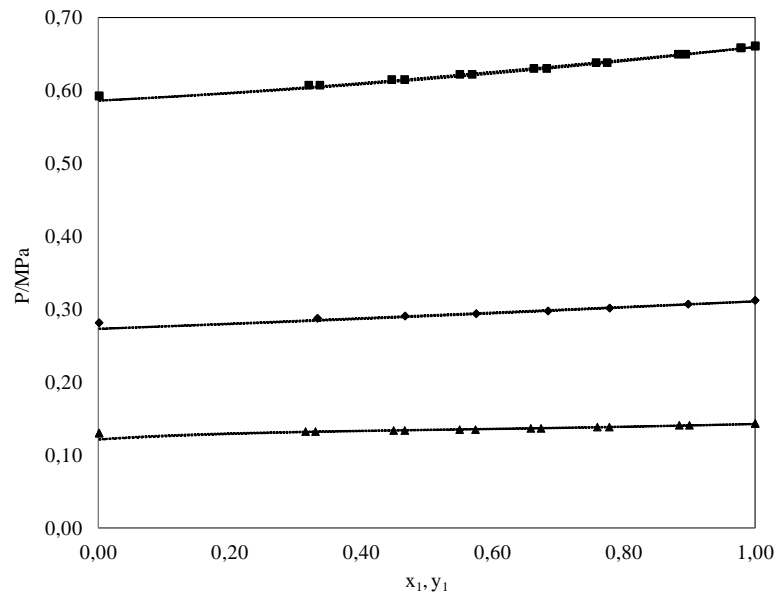

Figure 6. Compare the results of our work with experimental data [3] for R134a + R152a system, ( $\mathbf{\Delta}) 255 \mathrm{~K}$, (४) $275 \mathrm{~K}$ ( $298 \mathrm{~K}$, calculated from PR-MC-WS-NRTL model

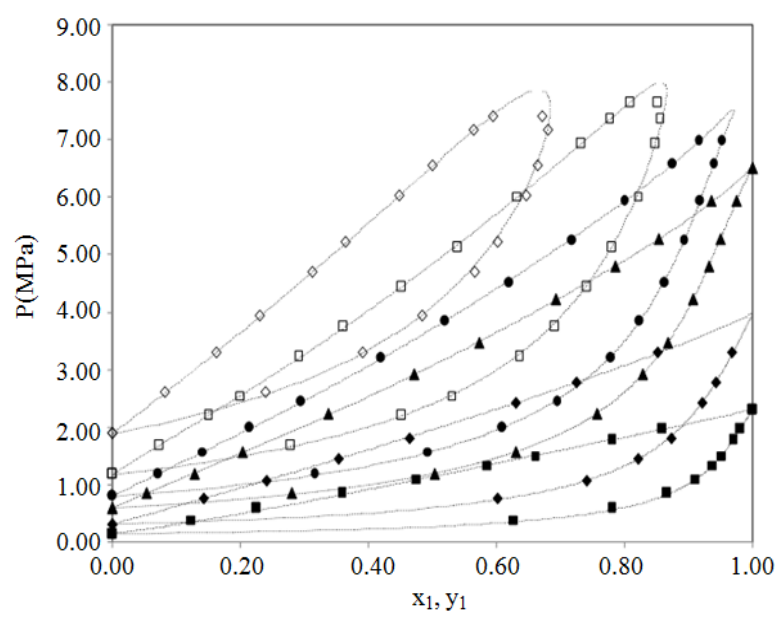

Figure 7. Compare the results of our work with experimental data [1] for R744 + R152a system, (घ) $258.44 \mathrm{~K}$, ( $\bullet$ ) 278.25 $\mathrm{K},(\boldsymbol{\Delta}) 298.84 \mathrm{~K},(\bullet) 308.37 \mathrm{~K},($ ) $330.30 \mathrm{~K},(\diamond) 303.15 \mathrm{~K}$; dotted line, calculated from PR-MC-WS-NRTL model

\section{DISCUSSION}

The mixture possesses an azeotrope when the value of $\alpha_{12} \approx 1$. Table 1 and $2(152 \mathrm{a}+\mathrm{R} 600$ and R744 + R152a, respectively) report both mole fractions and $\mathrm{K}_{1}$ partition coefficient calculated with our method. Experimental and calculated mole fractions and vapour pressures values of the azeotropic mixture (R152a + R600) are reported in Table 3.

Figure 3 gives the relative volatility with molar fraction and pressure.

The relative deviations of pressure and deviations of mole fraction were was $0.5 \%$ and $1 \%$, respectively. Figure 4 shows the deviations of $\mathrm{p}$ (pressure) and $x$ (composition) of R152a + R600 system. An excellent agreement (within1\%) with the experimental data from Jong Sung Lim and al [2].

Figures 5 and 6 present clearly the existence of azeotropic behavior that obtained by using experimental data and we confirm this by thermodynamic model.

Besides, we observed absence of azeotropic behavior in the mixture R744 + R152a (seen Figure 7) at all temperatures.

The results proved that there is a good agreement between the predicted values and the experimental data. The method can 
be applied to predict the azeotropic behaviour to other binary refrigerant mixtures.

\section{CONCLUSION}

This study proposed simple method adopted on experimental data and thermodynamic model. Two approaches are presented, in the first we use experimental data to predict the existence of an azeotrope and determine the critical point. In the second, we evaluate (confirm) the reliability of the first approach with thermodynamic model. Our thermodynamic model combines Peng-Robinson equation of state with Mathias-Copeman alpha function and the NRTL excess free energy model, using the WongSandler mixing rules.

From the obtained results and the discussion in this study, the main conclusions are:

- Robust methodology for different binary mixtures;

- Good prediction in binary mixtures;

- Ability to predicting the azeotropic point.

\section{ACKNOWLEDGMENT}

We are grateful to ARCME 2016 (The First Arab Conference on Mechanical Engineering).

\section{REFERENCES}

[1] Madani H., Valtz A., Coquelet C., Meniai A.H., Richon D. (2008). Vapor+liquid equilibrium data for (carbon dioxide + 1,1-difluoroethane) system at temperatures from (258 to 343 ) $\mathrm{K}$ and pressures up to about $8 \mathrm{Mpa}$, J. Chem. Thermodynamics, Vol. 40, pp. 1490-1494. DOI: 10.1016/J.JCT.2008.06.002

[2] Lim J.S., Seong G., Byunb H.S. (2007). Vapor-liquid equilibria for the binary system of 1,1-difluoroethane (HFC-152a) + n-butane (R-600) at various temperatures, Fluid Phase Equilibria, Vol. 259, pp. 165-172. DOI: $10.1016 /$ J.FLUID.2007.07.010

[3] Lim J.S., Park J.Y., Lee B.G., Lee Y.W. (2002). Phase equilibria of 1,1,1-trifluoroethane (HFC-143a) + 1,1,1,2-tetrafluoroethane (HFC-134a), and $+1,1$ difluoroethane (HFC-152a) at 273.15, 293.15, 303.15, and 313.15 K, Fluid Phase Equilibria, Vol. 193, pp. 29-39. DOI: $10.1016 / \mathrm{S} 0378-3812(01) 00632-\mathrm{X}$

[4] Ding Y.P., Robinson D.B. (1976). A new two-constant equation of state, Ind. Eng. Chem. Fundam, Vol. 15, pp. 59-64. DOI: $\underline{10.1021 / \mathrm{i} 160057 \mathrm{a} 011}$

[5] Mathias P.M., Copeman T.W. (1983). Extension of the Peng-Robinson equation of state to complex mixtures: evaluation of the various forms of the local

composition concept, Fluid Phase Equilibria, Vol. 13, pp. 91-108. DOI: $10.1016 / 0378-3812(83) 80084-3$

[6] Wong D.S.H., Sandler S.I. (1992). A theoretically correct mixing rule for cubic equations of state, AIChE J, Vol. 38, pp. 671-680. DOI: 10.1002/aic.690380505

[7] Henri R., Prausnitz J.M. (1968). Local compositions in thermodynamic excess functions for liquid mixtures, AIChE J, Vol. 24, pp. 135-144. DOI: 10.1002/aic.690140124

\section{NOMENCLATURE}

$P$

$\mathrm{R}$

$\mathrm{a}$

b

$v$

$\mathrm{c}_{1}, \mathrm{c}_{2}, \mathrm{c}_{3}$

$\mathrm{C}$

$\mathrm{N}$

$\mathrm{g}$

$k_{\mathrm{ij}}$

$K_{1}$

T

$x$

$y$

\section{Greek letters}

$\alpha$

$\mathrm{A}_{\mathrm{ji}}$

$\tau_{\mathrm{ij}}$

$\tau_{\mathrm{ji}}$

$\infty$

\section{Subscripts}

C

cal

az

$\exp$

$i, j$

1

2

\section{Superscripts}

E
Pressure

Gas constant

Parameter of the equation of state (energy parameter)

Parameter of the equation of state (molar co volume parameter)

Molar volume

Mathias-Copeman coefficient

Numerical constant equal to -0.62323

Number of experimental points

Molar Gibbs energy

Binary interaction parameter

Partition coefficient

Temperature

Liquid mole fraction

Vapor mole fraction

Alpha function

Non-randomness NRTL model parameter

NRTL model binary interaction parameter

NRTL model binary interaction parameter

Infinite pressure reference state

Critical property

Calculated property

Azeotrope property

Experimental property

Molecular species

Most volatile pure substance

Less volatile pure substance

Excess property 